dr Katarzyna Sztop-Rutkowska

Uniwersytet $w$ Białymstoku

Instytut Socjologii i Kognitywistyki

k.sztop@uwb.edu.pl

\title{
PROJEKTOWANIE OTWARTOŚCI - WYZWANIE NIE TYLKO DLA NAUKI
}

\section{DESIGNING OPENNESS - A CHALLENGE NOT ONLY FOR SCIENCE}

\begin{abstract}
Abstrakt
Coraz częściej można usłyszeć o polityce otwartości nie tylko w sferze nauki, ale również w zarządzaniu, edukacji czy rozwoju gospodarczym. Warto zastanowić się, dlaczego zwraca się uwagę na otwieranie danych zasobów publicznych. Jakie korzyści mamy z tego procesu jako obywatele czy klienci? W artykule zaprezentowano politykę otwartości jako element nowej kultury. Przedstawiono również przykłady prowadzenia polityki otwartości z Polski i innych krajów w kontekście zasobów publicznych, edukacji i gospodarki.
\end{abstract}

Słowa kluczowe: otwarte dane, otwarta administracja publiczna, wolna kultura, dobro wspólne, Internet.

\begin{abstract}
Increasingly, we not only hear about the politics of openness in the context of science but also in the context of city management, education and economic development. It is worth considering why it is worth opening data and various public resources. What benefits do we have as citizens or clients? In my article, I present the policy of openness as an element of a new culture. Interesting examples from Poland are presented, as well as from other countries to pursue an openness policy in the context of public resources, education and the economy.
\end{abstract}

Keywords: open data, open government, free culture, commons, Internet. 
„Kultura zawsze była remiksem. W końcu twórczość nie istnieje w próżni. Jeśli dziś możemy mówić, to tylko dzięki tym wszystkim, którzy byli przed nami. Za każdym naszym słowem stoi biblioteka, za każdym zdaniem czają się inne zdania. Znaczenie istnieje tylko w kontekście, w systemie odniesień. Bez kontekstu znaczenia nie ma. Dialog jest istotą kultury, bo kultura jest niczym innym jak rozłożonym w czasie procesem komunikacji społecznej”'.

\section{Wolna kultura}

Zjawiskiem łączącym wszystkie działania będące częścią polityki otwartości $w$ różnych instytucjach społecznych jest ruch wolnej kultury. Wiąże się on $\mathrm{z}$ upowszechnieniem Internetu, prostotą kopiowania i ponownego użycia wytworów kulturowych. Pojawienie się nowych technologicznych możliwości spowodowało szeroką dyskusję na temat praw autorskich i to one są źródłem dyskusji na temat wolnej kultury. Wolna kultura to „ruch społeczny promujący wolność dystrybucji i modyfikacji różnego rodzaju utworów za pomocą Internetu oraz innych mediów. Ruch ten sprzeciwia się nadmiernym - w opinii jego zwolenników - ograniczeniom zawartym w prawie autorskim, które wielu zwolenników ruchu uważa za czynnik hamujący kreatywność. System taki jest przez nich nazywany »kulturą zezwoleń «"2. Za przywódcę tego ruchu uznaje się amerykańskiego prawnika Lawrenca Lessiga, twórcę nowego typu praw autorskich - licencji Creative Commons i autora słynnej książki Wolna Kultura $^{3}$. Ruch wolnej kultury sprzeciwia się istniejącym zasadom związanym $\mathrm{z}$ prawami autorskimi, zwłaszcza $\mathrm{w}$ powiązaniu $\mathrm{z}$ przeniesieniem praw majątkowych na wielkie firmy i korporacje (np. wydawnicze). Widzi w tym ograniczenie wolności tworzenia, redystrybucji i twórczości. Stąd pojawiła się idea wolnych licencji, która obecnie ma bardzie wiele wariantów. I tutaj ma również początki idea otwartości w nauce, kulturze czy administracji.

1 J. Lipszyc: Infoholik. Kultra jest remiksem. „Dwutygodnik”. Tryb dostępu: https://www. dwutygodnik.com/artykul/2013-infoholik-kultura-jest-remiksem.html [3 października 2018].

2 Ruch wolnej kultury. W: Wikipedia: wolna encyklopedia. Tryb dostępu: https://pl.wikipedia.org/wiki/Ruch_wolnej_kultury [3 października 2018].

3 Przetłumaczona na język polski w specyficzny sposób dla idei wolnej kultury przez zespół dwudziestu tłumaczy i redaktorów wolontariuszy współpracujących na wiki projekcie. Treść książki dostępna jest na licencji Creative Commons Uznanie Autorstwa - Użycie niekomercyjne - Na tych samych warunkach. 


\section{Otwartość w różnych dziedzinach życia}

Działania wynikające z założeń ruchu wolnej kultury widzimy zarówno $\mathrm{w}$ idei otwartego rządu, postulatów otwierania instytucji kultury GLAM (galerie, biblioteki, archiwa, muzea), czy tworzeniu otwartych zasobów edukacyjnych (OER - Open Education Resources) i działaniach związanych $\mathrm{z}$ otwartą nauką . W zależności od dziedziny twórczości akcentuje się różne korzyści uwalniania treści, danych, dzieł.

W edukacji korzyści najczęściej powiązane są z kwestią równościową dzięki wolnemu dostępowi do wiedzy i materiałów wyrównują się społeczne szanse grup, które z różnych powodów mają trudniejszy dostęp do ważnych dóbr społecznych decydujących o miejscu w społeczeństwie w tym, właśnie do edukacji ${ }^{5}$. W głównym dokumencie ideowym tego ruchu, Kapsztadzkiej Deklaracji Otwartej Edukacji, napisano: „Dzięki nim [zasobom otwartej edukacji] edukacja jest łatwiej dostępna, szczególnie tam, gdzie brak pieniędzy na materiały edukacyjne. Wspierają one także kulturę uczestnictwa: wspólnego nauczania, tworzenia, dzielenia się i współpracy. Takiej właśnie kultury potrzebują zmieniające się społeczeństwa oparte na wiedzy"6.

W nauce otwartość wyników badań i publikacji naukowych zapewnia szybszy obieg informacji, niezbędny w nowoczesnych, szybko rozwijających się badaniach naukowych. Ponadto otwartość gwarantuje dostęp do wiedzy, która stanowi podstawę społeczeństwa opartego na wiedzy.

W gospodarce otwarte dane mogą być wykorzystywane do tworzenia nowych produktów i usług przez biznes, dzięki czemu generowana jest wartość dodana. Podkreśla się, że otwarte dane są bazą dla innowacyjnych produktów i usług.

4 Są to powszechnie dostępne zasoby takie jak: podręczniki, scenariusze lekcji, opracowania, udostępniane za darmo wraz z prawem do ich dalszego wykorzystywania i adaptacji. Rada Europy w rekomendacji z 2008 r. zaleciła stosowanie OER jako metody zwalczania cyfrowego wykluczenia i wyrównywania szans edukacyjnych.

5 Yaacov Hecht, twórca szkół demokratycznych w Izraelu opowiadał na jednej z konferencji Anna Lindh Foundation, jak dzięki zasobom otwartej edukacji na platformach MOOC wspierał edukację dzieci w wioskach Beduinów na pustyni Negew. Na podstawie otwartych platform edukacyjnych MOOC dzieci potrafiły w grupie rówieśniczej osiągnąć wysoki poziom wiedzy i umiejętności pracy grupowej.

6 Kapsztadzka Deklaracja Otwartej Edukacji - Ku otwartym zasobom edukacyjnym. Tryb dostępu: https://www.capetowndeclaration.org/translations/polish-translation [4 października 2018]. 
Otwartość dziedzictwa kulturowego sprawia, że zasoby kultury są obecne w życiu obywateli, wzrasta poziom świadomości kulturowej oraz wspierany jest przemysł kreatywny. Ułatwiona jest kreatywna kultura remiksu.

Otwartość danych publicznych sprzyja przejrzystości funkcjonowania administracji publicznej i ułatwia kontrolę obywatelską nad wydatkowaniem publicznych środków.

U podstaw ruchu wolnej kultury pojawia się pojęcie dobra wspólnego. Jedno z podstawowych założeń uzasadniających otwieranie i udostępnianie danych $\mathrm{w}$ wymienionych kontekstach opiera się przeświadczeniu, że materiały i działania finansowane ze środków publicznych powinny być dostępne dla wszystkich do swobodnego wykorzystania, gdyż stanowią nasze dobro wspólne. W wielu nurtach badawczych czy ideologicznych sam Internet i dobra w nim występujące tworzą kategorię tzw. nowych dóbr wspólnych (information commons). Jak pisze Justyna Hofmokl: „Wielu autorów wprost definiuje sam Internet jako jedno wielkie dobro wspólne, podkreślając wyjątkowość tego medium i postulując wprowadzenie odpowiednich regulacji, które umożliwiałyby ochronę Internetu przed zakusami sił dążących do prywatyzacji tej przestrzeni. Tak ujmowany Internet staje się również potencjalnym »trzecim miejscem « - obszarem działań jednostek, w którym możliwe jest tworzenie wspólnot i budowanie kapitału społecznego w oderwaniu od ograniczeń obecnych w świecie rzeczywistym"

Dla większości ludzi jakakolwiek wzmianka o „wspólnym” natychmiast przywołuje na myśl „tragedię wspólnego pastwiska”. Historia ta pokazuje, że własność prywatna pozwala na jej ochronę. Jak pisał David Bollier: „Ta przypowieść była politycznie wygodna, gdyż sugerowała niezbędność systemu prywatnej własności i rynku, aby powstrzymać ludzi przed rabunkowym wykorzystywaniem zasobów. Jeśli ludzie będą wyłącznymi właścicielami pastwisk, argumentowano, będzie im zależało na ich długoterminowej ochronie. W rzeczywistości jednak scenariusz wydarzeń opisany w tej przypowieści, w którym nie ma granic pastwiska, nie ma wspólnych zasad gospodarowania nim, nie ma społeczności jego użytkowników, opisuje nie tyle sytuację dobra wspólnego, ile dobra bezpańskiego"8.

7 J. Hofmokl: Internet jako dobro wspólne. Warszawa 2009, s. 8.

8 The Commons as a New/Old Paradigm for Governance, Economics and Policy. Remarks by D. Bollier. Commons Strategies Group for the American Academy in Berlin on December 4, 2012. Zob.: Dobro wspólne jako nowy paradygmat. W: P2P Foundation Wiki. Tryb dostępu: http://wiki.p2pfoundation.net/DOBRO_WSP\%C3\%93LNE_JAKO_ NOWY_PARADYGMAT [4 października 2018]. 
Badania Elinor Ostrom - pierwszej kobiety ekonomistki, która za swoje prace otrzymała nagrodę Nobla, pokazują, jak współpracująca społeczność może zarządzać zasobami w sposób zrównoważony, często bardziej efektywnie niż państwo czy rynek. Kwestie związane z wolnym udostępnianiem efektów działania człowieka są więc rdzeniem współczesnych sporów dotyczących własności i przyszłości systemów gospodarczych związanych choćby z koncepcją ekonomii współdzielenia (sharing economy).

\section{Otwarty rząd i otwarte dane}

Przyjrzyjmy się otwartym zasobom danych publicznych w powiązaniu $\mathrm{z}$ ideą otwartego rządu (open government) i ideą otwartych danych (Open Government Data - OGD). Idea otwartego rządu to „nowy sposób organizacji działań w państwie, który wykorzystuje cyfrowe narzędzia technologiczne i komunikacyjne, aby zwiększyć współudział obywateli w rządzeniu, a także wykorzystać ich wiedzę i zaangażowanie do skuteczniejszego

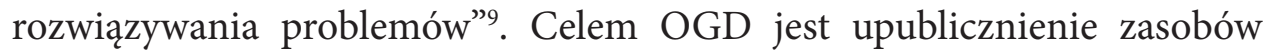
informacyjnych tworzonych przez administrację publiczną lub na jej zlecenie, oczywiście z wyłączeniem danych wrażliwych, a także swobodne wykorzystanie i rozpowszechnianie otwartych danych przez każdego obywatela czy mieszkańca. Termin OGD stał się popularny w 2008 r., po opublikowaniu przez zwolenników otwartości w Stanach Zjednoczonych zbioru zasad publikowania danych rządowych ${ }^{10}$.

Przedmiotem tych działań są szeroko rozumiane zasoby publiczne, czyli treści wytworzone przez podmioty publiczne lub finansowane ze środków publicznych. Zasoby te mogą mieć dowolny sposób wytworzenia i utrwalenia, mogą to być np.: raporty, mapy, fotografie, infografiki, materiały edukacyjne, filmy, nagrania dźwiękowe i innego typu utwory. W niektórych

9 Załącznik do Uchwały nr 12 Rady do Spraw Cyfryzacj. Warszawa, 1 kwietnia 2016 r. Krajowy plan działań Partnerstwa na rzecz Otwartego Rzadu (Open GovernmentPartnership). Tryb dostępu: http://otwartyrzad.org.pl/wp-content/uploads/2016/04/Załącznik-do-uchwały-nr-12-Krajowy-plan-działał-Partnerstwa-na-rzecz-Otwartego-Rządu. pdf [28 września 2018].

10 Powstające portale OGD bardzo często korzystają z usług serwisu GitHub. Współpracując z nim, stworzono dużą liczbę stron publicznych, np.: stronę biblioteki Europeana, strony miejskie Helsinek, Baltimore czy Bostonu. GitHub jest popularnym serwerem hostingowym umożliwiającym utrzymanie repozytoriów kodu źródłowego. 
Rysunek 1. Model otwartego zarządzania

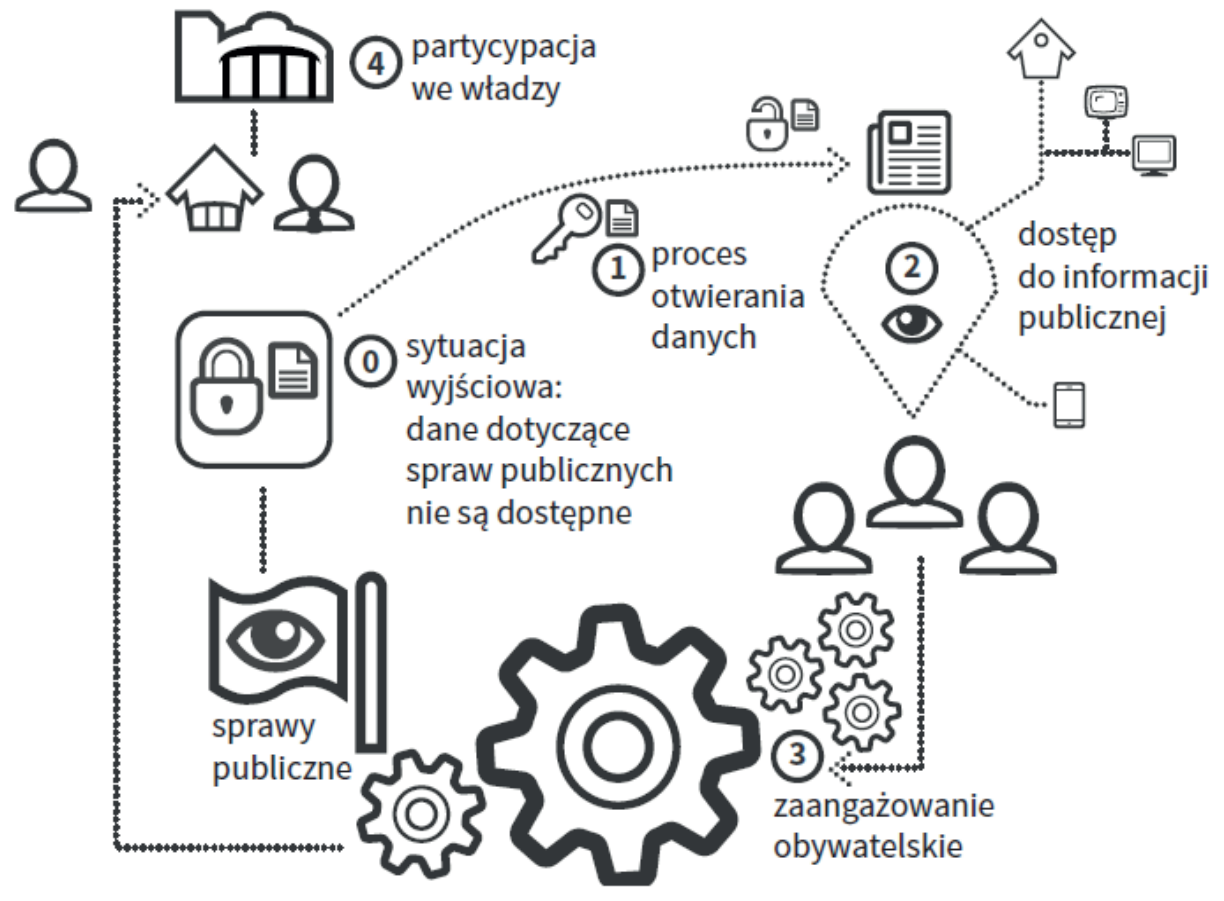

Źródło: Otwarty rzad w Polsce. Kulisy programu Opengov. Fundacja Projekt: Polska, Warszawa 2013.

wypadkach za zasoby publiczne uznaje się treści będące $\mathrm{w}$ posiadaniu instytucji publicznych - tak jest na przykład ze zbiorami dziedzictwa ${ }^{11}$.

W Polsce polityka otwierania danych niekiedy utożsamiana jest z konstytucyjnym dostępem do informacji publicznej ${ }^{12}$. Ma ona jednak szersze znaczenie. Udostępnianie informacji publicznej działa $\mathrm{w}$ dwóch trybach: wnioskowym i pozawnioskowym. W przypadku udostępniania informacji na wniosek, trzeba zaznaczyć, iż jest on procesem odformalizowanym, żądać informacji można w dowolny sposób (np. wysyłając list do urzędu). Informacja powinna być przekazana w ciągu 14 dni (w bardziej skomplikowanych sprawach do maksymalnie 2 miesięcy). Dla idei otwartych danych

11 Otwartość zasobów publicznych - pigułka wiedzy \#2. Tryb dostępu: https://centrumcyfrowe.pl/czytelnia/otwartosc-zasobow-publicznych-pigulka-wiedzy-2/ [29 września 2018].

12 Podstawowa ustawa regulująca to zagadnienie to Ustawa z dnia 6 września 2001 r. o dostępie do informacji publicznej. Dz.U. 2001, Nr 112, poz. 1198. 
istotniejszy jest proces uzyskiwania informacji bez konieczności składania wniosku. Jest to możliwe w przypadku informacji dostępnych w „Biuletynie Informacji Publicznej” (BIP) oraz w Centralnym Repozytorium Informacji Publicznej, czyli na portalu Danepubliczne.gov.pl lub innych podobnych portalach.

Jak wspomniano wcześniej, w polityce otwierania danych chodzi jednak o coś zdecydowanie więcej. Polityka otwartości jest procesem, który polega na udostępnianiu obywatelom danych gromadzonych przez miasto czy państwo i używaniu nowych technologii do wspierania przejrzystego rządzenia i włączania obywateli w proces podejmowania decyzji. Zakłada stopniowe uwalnianie nowych zbiorów danych publicznych, publikowanych w otwartych i uporządkowanych formatach, umożliwiających ich ponownie wykorzystywanie. Celem jest stworzenie warunków do innowacyjnego zastosowania informacji oraz inspirowanie przedsięwzięć o charakterze nie tylko społecznym, ale i ekonomicznym. Otwartość w administracji może być stosowana na wszystkich poziomach zarządzania: państwa, województwa, powiatu czy gminy.

\section{Otwarte dane - definicja}

Otwarte dane charakteryzują się następującymi cechami:

- dostępność - udostępnione bez żadnych ograniczeń dla szerokiego grona użytkowników (obywatele, firmy, uczelnie, instytucje) do dowolnych celów;

- upublicznienie w wersji źródłowej - dostępne w oryginalnej i niezmienionej formie, nie w postaci np.: analiz, podsumowań, skrótów czy streszczeń, tak aby możliwe było np. łączenie danych z różnych źródeł;

- kompletność - udostępnione w całości;

- aktualność - udostępnione na tyle szybko, aby zachować wartość tych danych;

- $\mathrm{w}$ formacie odczytywalnym maszynowo - udostępnione $\mathrm{w}$ formatach przeznaczonych do odczytu maszynowego i formacie otwartym (np. CSV czy XML);

- udostępnione niedyskryminująco - dostępne dla każdego bez konieczności rejestracji, weryfikacji tożsamości bez podawania hasła, loginu, czy podpisywania jakichkolwiek umów;

- dostępne bez ograniczeń licencyjnych - dane nie są przedmiotem praw autorskich, patentów, znaków towarowych lub tajemnicy handlowej 
i mogą być wykorzystywane $\mathrm{w}$ dowolnych celach bez konieczności ubiegania się o jakąkolwiek zgodę na ich używanie;

- niezastrzeżone - dostępne w formacie powszechnie stosowanym, który nie jest kontrolowany przez żaden podmiot ${ }^{13}$.

Kwestia polityki otwartości w miastach i państwach pojawiła się stosunkowo niedawno. W 2010 r. w Wielkiej Brytanii rozpoczął działanie portal data.gov.uk, którego zadaniem było zbieranie i udostępnianie danych przestrzennych uzyskiwanych z zasobów rządu brytyjskiego oraz zbieranie pomysłów zgłaszanych przez obywateli. Jednym z pomysłodawców powstania serwisu był Timothy Berners-Lee, który pomagał osobiście $\mathrm{w}$ jego promocji. Obecnie celem projektu jest publikowanie niemal wszystkich danych publicznych, $\mathrm{z}$ wyłączeniem danych osobowych, zbieranych na potrzeby administracji państwowej. W 2017 r. portal ten zawierał ogromną liczbę danych - 40 tys. zbiorów ${ }^{14}$.

Takie portale zaczęły pojawiać się $\mathrm{w}$ kolejnych państwach. Jeden z pierwszych powstał również w USA za czasów prezydentury Baracka Obamy. Tego typu serwisy są we wszystkich krajach UE (lista znajduje się w Załączniku 1.). Istnieją również wspólne projekty prezentujące zbiorczo dane z krajów UE. Warto zwrócić uwagę na takie portale jak:

1. Portal Otwartych Danych UE (EU Open Data Portal) ${ }^{15}$ został otwarty w 2012 r., jako punkt dostępu do danych gromadzonych przez instytucje i inne organy Unii Europejskiej. Dane te można swobodnie wykorzystywać zarówno do celów komercyjnych, jak i niekomercyjnych. Celem jest umożliwienie ponownego użycia (reuse) dokumentów Komisji Europejskiej. Do strony dodano również listę aplikacji wizualizujących dane, co usprawnia skorzystanie i uatrakcyjnia sam portal ${ }^{16}$.

2. Europejski Portal Danych ${ }^{17}$ to uniwersalny punkt dostępu w 24 językach urzędowych UE do danych opublikowanych przez organy

13 The 8 Principles of Open Government Data. Tryb dostępu: https://opengovdata.org/ [29 września 2018].

14 Data.gov.uk W: Wikipedia, the free encyclopedia. Tryb dostępu: https://en.wikipedia. org/wiki/Data.gov.uk [29 września 2018].

15 Portal Otwartych Danych UE. Tryb dostępu: https://data.europa.eu/euodp/pl/data [29 września 2018].

16 Zob. EU Open Data Portal. Tryb dostępu: http://data.europa.eu/euodp/en/apps [29 września 2018].

17 Europejski Portal Danych. Tryb dostępu: https://www.europeandataportal.eu/pl/homepage [29 września 2018]. 
administracji publicznej różnego szczebla w krajach europejskich. Stanowi on uzupełnienie Portalu Otwartych Danych UE.

\section{Korzyści z otwierania danych}

Polityka otwartości w zarządzaniu publicznym, choć jest relatywnie nowym pomysłem, staje się coraz bardziej popularna. Warto więc zadać sobie pytanie, o jakich korzyściach mówi się przy otwieraniu danych na poziomie rządu (państwa/miasta)?

\section{ZWIĘKSZENIE TRANSPARENTNOŚCI DZIALAŃ WEADZY}

Transparentność możemy definiować jako jawność zasobów i powiązań pomiędzy instytucjami a ich otoczeniem oraz ujawnianie procesu podejmowania decyzji. Transparentność nie oznacza stanu, w którym informacja publiczna została gdzieś udostępniona, np. w „Biuletynie Informacji Publicznej” lub też w teorii mogłaby zostać udostępniona na wniosek w trybie dostępu do informacji publicznej. Nie można również traktować minimalistycznie transparentności, jako konieczności składania sprawozdań budżetowych przez jednostki organizacyjne podległe samorządom ${ }^{18}$. Dane powinny być tak dostępne, by w prosty sposób, bez przetwarzania, można było z nich skorzystać. Transparentność jest ważnym czynnikiem aktywizującym mieszkańców i obywateli. Dzięki temu mogą oni dowiedzieć się, czy, np. w ich gminie jest czyste powietrze i jakie są priorytety w wydawaniu pieniędzy z budżetu. Takie działania wzmacniają zaufanie do władzy, ale również wpływają na zmniejszenie korupcji i zwiększenie racjonalności podejmowanych przez władzę działań.

\section{WZMOCNIENIE AKTYWNOŚCI PRODEMOKRATYCZNEJ I OBYWATELSKIEJ}

Kluczową sprawą w zarządzaniu np. miastem jest dobra i efektywna komunikacja z mieszkańcami i umożliwienie wpływu na podejmowane decyzje. Niepublikowanie danych, brak przejrzystej informacji prowadzi do niskiego poziomu zaufania i większej możliwości pojawiania się konfliktów społecznych, wynikających ze sprzeciwu wobec już podjętej decyzji. Mieszkańcy mogą czuć się zaskoczeni, że pewne posunięcia ich dotyczące zostały podjęte $\mathrm{w}$ zaciszu gabinetów, a w nie w procesie komunikacji. Ważna w tej komunikacji jest jej obustronność, interakcja. Jest to system

18 J. Glusman: Transparentność fundamentem demokracji. Tryb dostępu: https://publicystyka.ngo.pl/transparentnosc-fundamentem-demokracji [29 września 2018]. 
otwartych danych 2.0 - tworzących wokół siebie obustronną komunikację, angażujący odbiorców - obywateli, biznes. Bardzo ciekawym przykładem tego typu komunikacji związanej z polityką otwartości jest platforma Consul w Madrycie ${ }^{19}$. Jest to kompleksowa platforma używana do komunikacji urzędu i mieszkańców, dyskutowania i wybierania projektów do realizacji. Dane dostarczane przez platformę są zaczynem dyskusji w mieście (zarówno wirtualnych, jak i w rzeczywistości realnej). W tego typu działaniach bardzo ważne jest, by dane surowe były udostępniane w atrakcyjny i zrozumiały sposób. Ciekawe przykłady prezentacji danych można znaleźć w przypadku, np. pokazywania mieszkańcom budżetów miast ${ }^{20}$.

\section{Podwyższenie Jakości Zarządzania w ADMinistracji PUBLiCzNeJ}

Osoby wprowadzające polityki otwartości do polskich urzędów zwracają szczególną uwagę na kwestię silosowości zarządzania w administracji publicznej. Co to oznacza? Poszczególne wydziały czy departamenty bardzo rzadko ze sobą współpracują, wymieniając się informacjami i wspólnie rozwiązując problemy. Jednym z częstych sposobów zarządzania jest model „gorącego kartofla”, czyli przerzucania trudnego i nierozwiązanego problemu z poszczególnych działów urzędu, by pozbyć się go jak najszybciej z obszaru działań będących w zakresie kompetencji pracowników. Zarazem jednostki administracji są tak mocno zróżnicowane w obszarze sposobów działania, posiadanych zasobów informatycznych, świadomości liderów i pracowników w kwestiach informatycznych, że ich współpraca jest niezwykle trudna. Tomasz Nadolny, odpowiedzialny za wprowadzenie polityki otwartości w Gdańsku, pierwszym mieście w Polsce $\mathrm{z}$ wdrożoną polityką otwartości danych, zwraca często w swoich wypowiedziach uwagę na to, że prowadzenie wspólnej polityki otwartości w urzędzie porządkuje i ujednolica zasady wewnątrz całej organizacji, jasno określa rolę gospodarzy poszczególnych zbiorów danych i konieczności komunikacji pomiędzy poszczególnymi działami. Jest więc szansą na lepsze

19 Consul. Tryb dostępu: http://consulproject.org/en/ [29 września 2018].

20 Dowiedz się ile kosztuje nasze miasto. Budżet Słupska. Tryb dostępu: http://www. slupsk.pl/wp-content/uploads/2016/04/Budzet-Slupska-2016.pdf; Budżet Miasta Katowice na 2017 r. w pigułce. Tryb dostępu: https://www.katowice.eu/SiteAssets/miasto/bud\%C5\%BCet/budzet_Katowic_w_pigulce_2017.pdf [29 września 2018]; Bardzo ciekawy przykład z Dominikany, w formie komiksu. 30. Conozcamos el Presupuesto: Presupuesto Ciudadano: Proyecto de Ley de Presupuesto 2015. Tryb dostępu: https:// www.internationalbudget.org/wp-content/uploads/dominican-republic-citizens-budget-2015.pdf [29 września 2018]. 
i sprawniejsze zarządzanie urzędem jako całością, poprzez poprawienie komunikacji w samej instytucji. Ale jednocześnie jest procesem dość trudnym do przeprowadzenia.

Wprowadzenie polityki otwartości wpływa pozytywnie na ocenę administracji jako bardziej przyjaznej i efektywnej, wrażliwej na potrzeby obywatela. Wartością dodaną jest również redukcja kosztów i obciążeń biurokratycznych po stronie administracji publicznej, wynikających z konieczności przygotowania danych. Po prostu są one już tak przygotowane od początku, by można je ponownie wykorzystać.

\section{Wsparcie przy rozwiązywaniu szeroko pojętych problemów społecznych}

Udostępnienie danych prowadzić powinno do innowacyjnych sposobów rozwiązywania różnych problemów społecznych. Te efekty udostępniania są mocno powiązane $z$ budowaniem sieci zaangażowanych społeczników, programistów i innych osób związanych z projektowaniem aplikacji. Wzorcowym przykładem takich społeczności są lokalne grupy globalnej sieci Code for All, w Polsce znanej jako Koduj dla Polski ${ }^{21}$.

Kluczowym pojęciem, które należy wprowadzić jest civic tech, czyli społecznie zaangażowana technologia. Tomasz Nadolny definiuje ten rodzaj rozwiązań jako: „część technologii i społeczeństwa, która wykorzystując technologiczne narzędzia, dąży do poprawy warunków życia, oraz efektywności i sposobu działania sfery publicznej. Kluczowym pojęciem, które jest powiązane z civic tech jest współpraca, dzięki niej bowiem ludzie o najróżniejszym doświadczeniu, poglądach i specjalnościach zawodowych, budują rozwiązania dla innych ludzi"22.

Współpraca urzędu, społeczników i specjalistów z branży ICT jest realizowana często w ramach hackathonów lub hacknightów, czyli spotkań, podczas których grupa ludzi przez kilka godzin lub dni wspólnie projektuje i programuje rozwiązania technologiczne. Niekiedy dalsza praca nad projektami jest problematyczna, ponieważ wdrożenie rozwiązań trwa bardzo długo, ale są również przykłady efektywnych rozwiązań. W Gdańsku działa aplikacja BAND do wskazywania przez mieszkańców miejsc do

21 Koduj dla Polski. Tryb dostępu: https://kodujdlapolski.pl/projekty/ [29 września 2018].

22 T. Nadolny: Co właściwie oznacza „Civic Tech”? Tryb dostępu: https://medium.com/@ jonaszek/co-w\%C5\%82a\%C5\%9Bciwie-oznacza-civic-tech-d502f57506f. [29 września 2018]. 
nasadzeń drzew, aplikacja NA4ŁAPY do wspierania procesu adopcji zwierząt z miejskiego schroniska. Inne projekty o charakterze ogólnopolskim są powiązane często z ideą kontroli władzy, np. Sejmometrr ${ }^{23}$, Moje Państwo ${ }^{24}$ czy Mam Prawo Wiedzieć ${ }^{25}$. Organizacje pozarządowe testują także rozwiązania oparte na uzupełnianiu danych otwartych przez informacje zbierane w modelu crowdsourcingu - jak to ma miejsce w projektach Naprawmy.to ${ }^{26}$ czy Otwarte Zabytki ${ }^{27}$.

\section{Korzyści ekonomiczne}

Z ekonomicznego punktu widzenia udostępnianie danych sektora publicznego przynosi określone korzyści. Komisja Europejska oszacowała korzyści ekonomiczne płynące z rynku otwartych danych: w latach 2016-2020. Oczekuje się, że wielkość rynku otwartych danych wzrośnie o 36,9\%, do wartości 75,7 mld euro w $2020 \mathrm{r}$. i wyniesie 325 mld euro ${ }^{28}$.

Ekonomiczna wartość informacji sektora publicznego wynika wprost z faktu, że w gospodarce opartej na informacji posiadana wiedza jest zawsze źródłem przewagi konkurencyjnej ${ }^{29}$. Wartość dodaną należy przy tym rozumieć nie tylko w kategoriach ekonomicznych. Tak jak wcześniej wspomniano, wykorzystanie otwartych danych może również służyć rozwiązywaniu szeroko pojętych problemów społecznych, wzmacnianiu pozycji obywateli wobec władzy czy wreszcie większej wydajności samej administracji.

W analizie pozytywnych efektów gospodarczych udostępniania danych instytucji publicznych, zwraca się uwagę przede wszystkim na:

- obniżenie kosztów prowadzenia działalności gospodarczej dzięki temu, że jest łatwiejszy dostęp do informacji o regulacjach, funkcjonowaniu administracji publicznej i wymogach formalnych, a także do źródeł naukowych obniżających koszty działalności badawczo-rozwojowej;

23 Tryb dostępu: https://sejmometr.pl/ [29 września 2018].

24 Tryb dostępu: https://mojepanstwo.pl/ [29 września 2018].

25 Tryb dostępu: https://mamprawowiedziec.pl/ [29 września 2018].

26 Tryb dostępu: http://www.naprawmy.to/ [29 września 2018].

27 Tryb dostępu: https://otwartezabytki.pl/ [29 września 2018].

28 Europejski portal danych. Tryb dostępu: http://www.europeandataportal.eu/pl/content/ creating-value-through-open-data [29 września 2018].

29 Za: Rynek produktów, usług i treści cyfrowych opartych na ponownym wykorzystaniu informacji sektora publicznego (ISP) w Polsce. WISE. Centrum Cyfrowe Projekt: Polska, Warszawa 2015, s. 9. 
- budowanie ekosystemu innowacji i tworzenie nowych produktów.

Przykładowo, wspomniana już strona brytyjskiego rządu data.gov.uk pozwalała na pobranie już w 2013 r. 314 aplikacji (w tym, np. mobilną wyszukiwarkę parkingów czy London Traffic - aplikację udostępniającą zdjęcia z ponad 700 kamer rozmieszczonych w całej brytyjskiej stolicy) ${ }^{30}$.

Badania amerykańskiego think tanku The Governance Lab ${ }^{31}$ pokazuja jednak pewną problematyczność tych ekonomicznych skutków udostępniania danych administracji publicznej. Zazwyczaj jest tak, że pewne zbiory danych są wykorzystywane o wiele częściej, a niektóre z nich (a nawet większość) nie są w ogóle użytkowane ponownie. Oznacza to, że na razie niewielka część danych jest relatywnie o wiele częściej używana i znajduje komercyjne zastosowania.

Warto sobie zadać również pytanie, kto najczęściej korzysta w komercyjny sposób z danych? W przypadku amerykańskich danych w pierwszej kolejności korzystają firmy zajmujące się systemami archiwizacji, porządkowania, udostępniania i analizowania danych. W dużej części są wykonawcami zleceń rządowych, przygotowując, np. infrastrukturę informatyczną, umożliwiającą bardziej przyjazne publikowanie informacji sektora publicznego. Sytuacja ta ma jednak jeszcze większe znaczenie w kontekście małych innowacyjnych firm (start-upów) w tej dziedzinie. Dzięki pracy nad udostępnianymi danymi zdobywają one doświadczenie i wykorzystują nowatorskie narzędzia do porządkowania zbiorów Big Data. W ten sposób obniżany jest próg wejścia na rynek dla małych firm analitycznych i wzrasta konkurencyjność, która pozytywnie wpływa na innowacje i jakość oferowanych usług. Kolejnym typem podmiotów, które komercyjnie korzystają z dostępu do informacji publicznej, są firmy i instytucje z sektora finansowego i usług dla biznesu, które są dobrze przygotowane do obróbki i analizy informacji ${ }^{32}$. Przykładowe aplikacje zostały przedstawione w Załączniku 2.

30 J. Papińska-Kacperek, K. Polańska: Analiza zaawansowania realizacji idei open government data w wybranych krajach. „Zeszyty Naukowe Uniwersytetu Szczecińskiego. Studia Informatica" 2015, nr 37, s. 103-114.

31 Zob. Open Adata 500 Global Network. Tryb dostępu: www.opendata500.com [29 września 2018].

32 Przykłady amerykańskich firm/produktów opartych o dane (zwłaszcza z poziomu federalnego) są na stronie: Data.gov. Tryb dostępu: https://www.data.gov/impact/ [29 września 2018] i z UE: EU Open Data Portal. Tryb dostępu: http://data.europa.eu/euodp/en/ apps [29 września 2018]. 


\section{Standardy otwartych danych}

Zwiększająca się popularność otwierania danych instytucji publicznych sprawiła, że Ministerstwo Cyfryzacji wprowadziło standardy otwartych danych $w$ administracji publicznej ${ }^{33}$ :

1. Standard API. Standard określa minimalne, rekomendowane zalecenia, dotyczące interfejsu programistycznego aplikacji dostępu do baz danych, które przechowują dane publiczne. Został stworzony po to, aby administracja publiczna udostępniała swoje dane przez API według jednolitego standardu.

2. Standard bezpieczeństwa. Kluczową kwestią jest dobór odpowiednich technik anonimizacji. Standard ten obejmuje m.in.: minimalne czynności dotyczące udostępniania danych do ponownego wykorzystywania, grupy danych podlegające nieograniczonemu ponownemu wykorzystywaniu, dane podlegające anonimizacji i pseudonimizacji oraz sposoby doboru technik.

3. Standard techniczny. Wskazuje wymagania techniczne dla danych publicznych, w tym dla pięciu poziomów otwartości danych (według schematu Tima Bernersa-Lee) i formatów danych wraz z przykładami. Standard obejmuje także wymagania dotyczące formatowania określonych typów danych, jak np. dane adresowe czy daty.

4. Standard prawny. Zalecenia dotyczą m.in. kwestii licencjonowania oraz ochrony praw autorskich. Standard porusza także kwestie barier w udostępnianiu danych publicznych w sposób otwarty, filarów otwartości danych oraz wzorca otwartości.

\section{Podsumowanie}

Jak widać ruch otwartej kultury wpływa również na sposób rozumienia idei dobrego rządzenia (e-governance) i szerokiego włączania obywateli w podejmowanie decyzji na poziomie lokalnym czy krajowym. Dodatkowym pozytywnym efektem jest wpływ na gospodarkę i powstawanie nowych firm i produktów. Projektowanie otwartości w tak różnych dziedzinach, jak: edukacja, nauka czy polityka, ma w sobie ogromny potencjał zmiany społecznej i upodmiotowiania jednostek, i grup. Jest ona obarczona wieloma trudnościami, ale widoczne korzyści sprawiają, że z pewnością warto wysiłek otwierania zasobów ponieść.

33 Otwarte dane. Tryb dostępu: https://dane.gov.pl/article/1219 [29 września 2018]. 


\section{Załącznik 1.}

Portale danych otwartych w poszczególnych miastach i państwach

Portale lokalne:

1. Warszawa: danepowarszawsku.pl

2. Gdańsk: otwartygdansk.pl

3. Wrocław: wroclaw.pl/ open-data

4. Gdańsk: bip.poznan.pl/bip/ /api

5. Starachowice: otwarte. starachowice.eu

Portale otwartych danych państw członkowskich UE:

1. Austria: data.gv.at

2. Belgia: data.gov.be

3. Wielka Brytania: data.gov.uk

4. Bułgaria: opendata.government.bg

5. Chorwacja: data.gov.hr

6. Cypr: data.gov.cy
7. Czechy: opendata.cz

8. Dania: portal.opendata.dk

9. Estonia: opendata.ee

10. Finlandia: avoindata.fi

11. Francja: data.gouv.fr

12. Grecja: data.gov.gr

13. Hiszpania: datos.gob.es

14. Holandia: data.overheid.nl

15. Irlandia: data.gov.ie

16. Łotwa: opendata.gov.lt

17. Malta: data.gov.mt

18. Niemcy: govdata.de

19. Portugalia: dados.gov.pt

20. Rumunia: data.gov.grdata. gov.ro

21. Słowacja: data.gov.sk

22. Słowenia: nio.gov.si/nio/

23. Szwecja: oppnadata.se

24. Włochy: dati.gov.it

\section{Załącznik 2.}

Przykłady komercyjnego wykorzystania danych sektora publicznego na rynku amerykańskim i polskim.

\section{Aplikacje komercyjne:}

Aplikacja GoodGuide pozwala konsumentom pozyskiwać informacje na temat poszczególnych produktów od strony ich wpływu na zdrowie, środowisko czy wpływu społecznego. GoodGuide zatrudnia specjalistów, którzy oceniają poszczególne produkty (głównie żywność, zabawki, produkty higieny osobistej oraz wyposażenie domów), korzystając $\mathrm{z}$ informacji na ich temat dostępnych poprzez opisy producentów, ale także - i co ważniejsze - poprzez informacje wytworzone przez agencje testujące i dopuszczające poszczególne produkty do obrotu rynkowego. Zob.: https://www.goodguide.com 
Accuweather to amerykańska firma zajmująca się sporządzaniem prognoz pogody. Działalność biznesowa firmy opiera się na dostarczaniu usług meteorologicznych. Liczba jej klientów sięga 175 tys. (media, biznes, agencje rządowe). Oprócz tego firma prowadzi własny, bezpłatny internetowy serwis meteorologiczny oraz 24-godzinny kanał telewizyjny The Local AccuWeather Channel obecny na 56 lokalnych rynkach medialnych w USA. Działalność obu jest finansowana z wpływów z reklam. Zob.: http:// www.accuweather.com/

AreaVibes to amerykańska strona internetowa, na której w oparciu o dane społeczne został stworzony ranking 22 tys. miast i dzielnic w USA. Głównym celem strony jest ocena „mieszkalności” (ang. livability) miast i dzielnic w USA. Strona przeznaczona jest dla osób planujących przeprowadzkę do innego miasta/regionu i ma być pomocna przy dokonywaniu wyboru nowego miejsca zamieszkania. AreaVibes jest serwisem darmowym, a jego działalność jest finansowana $\mathrm{z}$ wpływów z reklam. Zob.: http://www.areavibes.com/

Polski portal internetowy Prześwietl.pl jest narzędziem, które pomaga sprawdzić wiarygodność biznesową potencjalnych partnerów biznesowych oraz strukturę danej firmy. Oferta serwisu skierowana jest do osób z branży biznesu. Rejestracja w portalu oraz usługi podstawowe są darmowe, pobierane są jednak opłaty za wykupienie abonamentów, dzięki którym użytkownik ma dostęp do większej liczby informacji. Zob.: https://przeswietl.pl

ZnajdzKsiege.pl to polski serwis internetowy, dzięki któremu można znaleźć i pobrać dowolną księgę wieczystą podając adres nieruchomości lub numer działki. Przeznaczony jest dla osób działających na rynku nieruchomości, a także dla wszystkich podmiotów zainteresowanych informacjami na temat nieruchomości w Polsce. Finansowanie serwisu jest oparte o opłaty za każdorazowe ściągnięcie księgi wieczystej. Zob.: http://www. znajdzksiege.pl/

\section{Aplikacje o charakterze społecznym:}

Hurricane app to darmowa aplikacja mobilna stworzona przez amerykański oddział Czerwonego Krzyża. Korzystająca z danych amerykańskiej Narodowej Administracji Oceanu i Atmosfery. Aplikacja skierowana jest do wszystkich mieszkańców USA, którzy zamieszkują obszary zagrożone huraganami. Oprócz funkcji alertu w przypadku zbliżającego się kataklizmu i spersonalizowej prognozy pogody, aplikacja zawiera również wskazówki i instrukcje dotyczące postepowania w przypadku nadejścia huraganu, bazę danych schronisk Amerykańskiego Czerwonego Krzyża oraz funkcję 
wysyłania za pomocą jednego „dotknięcia” wiadomości do bliskich, zapewniającej ich o bezpieczeństwie użytkownika. Aplikacja dostępna jest za darmo. Zob.: http://www.redcross.org/mobile-apps/hurricane-app Polska aplikacja jakdojade.pl pomagająca przemieszczającym się komunikacją miejską w wybranych miastach zaplanować swoją podróż. Zob.: https://jakdojade.pl/

\section{Bibliografia}

1. Budżet Miasta Katowice na 2017 r. w pigutce. Tryb dostępu: https://www.katowice.eu/SiteAssets/miasto/bud\%C5\%BCet/budzet_Katowic_w_pigulce_2017. pdf [29 września 2018].

2. Centrum Cyfrowe. Tryb dostępu: https://centrumcyfrowe.pl/czytelnia/otwartosc-zasobow-publicznych-pigulka-wiedzy-2/ [29 września 2018].

3. The Commons as a New/Old Paradigm for Governance, Economics and Policy. Remarks by D. Bollier. Commons Strategies Group for the American Academy in Berlin on December 4, 2012. Dobro wspólne jako nowy paradygmat. W: P2P Foundation Wiki. Tryb dostępu: http://wiki.p2pfoundation.net/DOBRO_ WSP\%C3\%93LNE_JAKO_NOWY_PARADYGMAT [4 października 2018].

4. Conozcamos el Presupuesto: Presupuesto Ciudadano: Proyecto de Ley de Presupuesto 2015. Tryb dostępu: https://www.internationalbudget.org/wp-content/ uploads/dominican-republic-citizens-budget-2015.pdf [29 września 2018].

5. Consul. Tryb dostępu: http://consulproject.org/en/ [29 września 2018].

6. Creating Value through Open Data. Study on the Impact of Re-use of Public Data Resources. EU 2015. Tryb dostępu: https://www.europeandataportal.eu/ sites/default/files/edp_creating_value_through_open_data_0.pdf [29 września 2018].

7. Data.gov. Tryb dostępu: https://www.data.gov/impact/ [29 września 2018].

8. Data.gov.uk W: Wikipedia, the free encyclopedia. Tryb dostępu: https://en.wikipedia.org/wiki/Data.gov.uk [29 września 2018].

9. Dowiedz się ile kosztuje nasze miasto. Budżet Stupska 2016. Tryb dostępu: http://www.slupsk.pl/wp-content/uploads/2016/04/Budzet-Slupska-2016.pdf [29 września 2018].

10. The [eight] Principles of Open Government Data. Tryb dostępu: https://opengovdata.org/ [29 września 2018].

11. EU Open Data Portal. Tryb dostępu: http://data.europa.eu/euodp/en/apps [29 września 2018].

12. Europejski Portal Danych. Tryb dostępu: https://www.europeandataportal.eu/ pl/homepage [29 września 2018].

13. Glusman J.: Transparentność fundamentem demokracji. Tryb dostępu: https:// publicystyka.ngo.pl/transparentnosc-fundamentem-demokracji [29 września 2018].

14. Hofmokl J.: Internet jako dobro wspólne. Warszawa 2009.

15. Kapsztadzka Deklaracja Otwartej Deklaracji. Tryb dostępu: https://www.capetowndeclaration.org/translations/polish-translation [4 października 2018]. 
16. Koduj dla Polski. Tryb dostępu: https://kodujdlapolski.pl/projekty/ [29 września 2018].

17. Krajowy Plan działań Partnerstwa na rzecz Otwartego Rządu. Tryb dostępu: http://otwartyrzad.org.pl/wp-content/uploads/2016/04/Załącznik-do-uchwały-nr-12-Krajowy-plan-działań-Partnerstwa-na-rzecz-Otwartego-Rządu.pdf [28 września 2018].

18. Lipszyc J.: Infoholik. Kultra jest remiksem. „Dwutygodnik”. Tryb dostępu: https://www.dwutygodnik.com/artykul/2013-infoholik-kultura-jest-remiksem.html [3 października 2018].

19. Nadolny T.: Co właściwie oznacza „Civic Tech”? Tryb dostępu: https://medium.com/@jonaszek/co-w\%C5\%82a\%C5\%9Bciwie-oznacza-civic-tech-d502f57506f [29 września 2018].

20. Open Adata 500 Global Network. Tryb dostępu: www.opendata500.com [29 września 2018].

21. Otwarte dane. Tryb dostępu: https://dane.gov.pl/article/1219 [29 września 2018].

22. Otwarty rzad w Polsce. Kulisy programu Opengov. Fundacja Projekt: Polska. Warszawa 2013.

23. Papińska-Kacperek J., Polańska K.: Analiza zaawansowania realizacji idei open government data $w$ wybranych krajach. „Zeszyty Naukowe Uniwersytetu Szczecińskiego. Studia Informatica” 2015, nr 37, s. 103-114.

24. Portal Otwartych Danych UE. Tryb dostępu: https://data.europa.eu/euodp/pl/ data [29 września 2018].

25. Ruch wolnej kultury. W: Wikipedia: wolna encyklopedia. Tryb dostępu: https:// pl.wikipedia.org/wiki/Ruch_wolnej_kultury [3 października 2018].

26. Rynek produktów, usług i treści cyfrowych opartych na ponownym wykorzystaniu informacji sektora publicznego (ISP) w Polsce. WISE. Centrum Cyfrowe Projekt: Polska. Warszawa 2015.

27. Ustawa z dnia 6 września 2001 r. o dostępie do informacji publicznej. Dz.U. 2001, Nr 112, poz. 1198. 